\section{Live and let live}

\author{
BeverlyE. Griffin
}

Emerging Viruses. Edited by S. S. Morse. Oxford University Press: 1993. Pp. 317. $£ 32.50, \$ 39.95$.

A RECENT leading article in The Times of London (5 February 1994) attributes to Sir Peter Medawar the description of a virus as "bad news wrapped in protein". But is there no such thing as a good virus? The answer depends on the relationship of an individual to the viral host, for viruses are complete parasites and depend entirely for their existence on their host. If, for example, the host is deemed to be bad, then one's attitude might be altered in favour of the virus. It is this philosophy that has led to the examination of a role for insect viruses as 'insecticides', protecting valuable crops from being destroyed. So, because every living species has its own battery of viruses, from man's point of view there can be such things as good viruses. But by and large viruses are 'bad news' for us; it is from this point of view that Emerging Viruses is written.

The basic message of the book is that although many viruses may adopt largely passive roles in their native host, this passivity can be perturbed in a number of ways. The routes considered involve moving the virus via its host to a new environment, one formerly alien to the virus, or the passage of a virus from its natural host to a new species. In both routes, a delicate balance is disturbed, and the virus may become a deadly enemy. Adaptation to the host is part of the life cycle of any virus, but this is a process that requires time (decades or longer).

Last year in Nature $(\mathbf{3 6 4}, \mathbf{2 0 1}$; 1993) I reviewed a book by a US journalist about emerging viruses ( $A$ Dancing Matrix: Voyages Along the Viral Frontier by R. M. Henig, Knopf, 1993). This was, on ba-

\begin{tabular}{|l|}
\hline \multicolumn{1}{|c|}{ New in paperback } \\
Nuclear Cholces: A Citizen's Guide to \\
Nuclear Technology by Richard Wolfson \\
(revised edn). Reviewed in Nature 353, \\
222 (1991). MIT Press, $£ 17.95$, \\
$\$ 19.95$. \\
The Space Telescope: A Study of NASA, \\
Sclence, Technology and Politics by \\
Robert W. Smith. Now with a new \\
afterword detailing the project's \\
problems since its 1990 launch, but \\
written before the recent successful \\
mission to put Hubble into focus. CUP, \\
£16.95, \$24.95. \\
The Bamboos by F. A. McClure, now with \\
a new foreword and introduction. A \\
classic of botany and horticulture, first \\
published in 1966 . Smithsonian \\
Institution Press, $\$ 16.95$.
\end{tabular}

NATURE · VOL 368 - 3 MARCH 1994 lance, a readable and stimulating book. Henig made frequent references to conversations with $\mathrm{S}$. S. Morse, a scientist at the Rockefeller University and editor of Emerging Viruses. It was clear that, to Henig, Morse was a sort of guru with whom she checked her ideas. Despite its occasional technical flaws, Henig's book covered a great deal of the territory now covered by Morse, and often better. Emerging Viruses suffers by being a badly edited multi-authored volume, the whole distinctly poorer than the sum of its parts.

The book had its origins in a conference held in Washington DC in May 1989, although it contains additional and updated contributions. There are 28 chapters and 45 authors, most of them from US institutions. (That is in itself not unreasonable: with the exception perhaps of the Pasteur Institute in France and the Ivanovsky Institute of the former Soviet Union, little attention outside the United States has unfortunately been paid to the subject as it relates to humans). Individual chapters are rather artificially grouped under topics that supposedly define them. But the book as a whole impresses one more as a random-chapter stapling job than a coherent whole.

Having said this, I would have to agree with the editor and contributors that where the field of viruses is concerned, we cannot afford to be complacent, so a book covering the topic of the changing patterns of viruses and the emergence of unknown (not necessarily new) ones deserves to be written and carefully read. This point is strongly and convincingly made in chapter 27 by Donald A. Henderson of the US Office of Science and Technology Policy. (Why does this splendid chapter not appear earlier?) To quote him:

The recent emergence of AIDS and dengue hemorrhagic infections, among others, are serving usefully to disturb our ill-founded complacency about infectious diseases. Such complacency has prevailed in this country (USA) throughout much of my career. . . It is evident now, as it should have been then, that mutation and change are facts of nature, that the world is increasingly interdependent, and that human health and survival will be challenged, ad infinitum, by new and mutant microbes, with unpredictable pathophysiological manifestations. . How are we to detect these at an early date so as to be able to devise appropriate preventive and therapeutic modalities? What do we look for? What types of surveillance and reporting systems can one devise?

Virology books can generally be divided into two types: those that deal with what viruses are, and those that deal with what they do. Emerging Viruses falls into neither of these categories. It is a specialist book for specialists, dealing almost exclusively with the so-called RNA viruses, that is, those viruses whose genetic information is carried in RNA, not DNA. These are the viruses whose rate of mutation is sufficiently fast that controlling them, or predicting their behaviour, is well-nigh impossible. The most widely studied and to some extent the most important at the moment are influenza and HIV, considered by several contributors. Among the numerous provocative and well-written chapters on RNA viruses, there is an excellent one by J. J. Holland that deals biologically and mathematically with, on the one hand, the extreme genetic variability of RNA viruses and, on the other, the most plausible explanations for why DNA viruses are not equally plastic. Variability, or mutation, is an exceedingly important topic for any discipline focusing on intervention, and Holland emphasizes how little we really know about 'natural' mutation and in particular why it can vary so dramatically among different RNA viruses or within the genome of any one of them. High mutation rate means that no RNA virus population is a single entity, but is rather (in Manfred Eigen's term) a "quasi-species".

Emerging Viruses mainly deals with human viruses, or viruses that have recently crossed over into man from other species. In one of the few chapters on the more stable DNA viruses, Frank Fenner, the Australian doyen of virology, discusses a pox virus that is indigenous to several species of monkeys and can also be carried by squirrels. 'Human monkey pox', as it is called, can produce symptoms in unvaccinated humans similar to those produced by smallpox. Following the World Health Organization (WHO) smallpox eradication scheme, and subsequent discontinuation of vaccination, 386 cases of monkey pox in Zaïre (up to 1986) were identified. This is an illustration of a virus menacingly changing its natural host range, a phenomenon more prevalent in, but not restricted to, RNA viruses. Vaccines against smallpox are, indeed, effective against human monkey pox, but the WHO programme has ended. There is one chapter devoted to plant viruses - can or do these ever cross over to man? - and another to the seal virus plague that appeared spontaneously and dramatically in northern Europe in 1988.

Much of the book, however, focuses on the new human diseases that have come (to the United States) from tropical countries, or arisen following man-made alterations in the ecosystem. Some of these outbreaks may indeed be attributable to our naivety about viruses. Outbursts are not necessarily new phenomena, as Howard Temin notes in the introduction to his chapter on retroviruses: sailing ships brought yellow fever from Africa to the Americas in the seventeenth and eighteenth centuries, the disruptions of the First World War coincided with the great influenza pandemic, and so on. Temin and others, in considering the vast 
changes in urbanization, population explosions in parts of the world, altering life styles (including jet travel) and so on, wonder how we have escaped with so few pandemics. Again and again, the authors argue that we are at the mercy of viruses, not the other way around. That does not mean we should be defeatist, and I suspect that many of the contributors are concerned with seeing that we are not. But individuals can do little. It requires surveillance at government levels, which means money invested in epidemiology, tropical medicine and communication. Outside the United States, who at high level is considering such problems? Will it prove a regrettable mistake that the UK Medical Research Council closed down its Tropical Medicine Board a few years ago?

Government safety inspectors in Birmingham (England) monitored closely by interested, but not very knowledgeable, scientific correspondents in the daily press, have recently been concerned with what is viewed as a breach of safety rules involving genetic manipulation of a viral component (see Nature 367, 499; 1994). One research laboratory of the university has apparently been closed. The Times (op. cit.) used this incident for an attack on academic freedom, censoring scientists for "still inhabiting the sequestered world described by C. P. Snow". Although there may be some justification in this criticism, it seems equally imperative to pay attention to the fact that viruses are manipulated constantly in nature, in a manner well beyond our control and on a scale that transcends many times the efforts of a single laboratory. Let us hope, globally, that our various Health and Safety Executives, and our press, are alert to this fact. How many of them will read this book? May I close by drawing it to their attention?

Beverly E. Griffin is in the Department of Virology, Royal Postgraduate Medical School, Hammersmith Hospital, Du Cane Road, London W12 ONN, UK.

\section{A physicist's tour of chaos}

\section{Paul Glendinning}

Chaos in Dynamical Systems. By Edward Ott. Cambridge University Press: 1993. Pp. 385. £45.00, \$69.95 (hbk); £16.95. $\$ 29.95$ (pbk).

THE term 'chaos' was first used in the context of dynamical systems by T. Y. Li and J. A. Yorke in 1975 (Am. Math. Monthly 82, 985-992). Ever since, the group at the University of Maryland (Yorke, C. Grebogi, E. Ott and others) has been at the forefront of work on applied dynamical systems. Ott's book collects together many of the results obtained at Maryland (and a few from other sources) to provide a stimulating selection of topics that could be taught à la carte in postgraduate courses. The book is given unity by a preoccupation with scaling arguments, but covers almost all aspects of the subject (dimensions of strange attractors, transitions to chaos, thermodynamic formalism, scattering, quantum chaos and so on).

The study of chaos, and dynamical systems in general, has always been multidisciplinary. Ott approaches mathematical phenomena as a physicist, using the computer as his experimental tool. There is little attempt to make statements mathematically precise and, as in many physical textbooks, the reader is expected to acquire a great deal of knowledge on trust. For example, by looking at computer simulations we are shown that the attractor for the Hénon map, a simple map of the plane to itself, is geometrically complicated ('fractal') and "hence [that the map] has a strange attractor". The fact that this is not an established result for Ott's example goes unmentioned. (It is only very recently that rigorous results have been obtained on the existence of strange attractors for some Hénon maps and these serve only to demonstrate how many other complications are possible.) Nevertheless, his description provides an excellent, intuitive account of chaos, which is essential to developing scientists matical niceties that have been swept under the carpet.

These remarks are not intended as criticism. What Ott demonstrates is the power of the physical approach to mathematics. It allows him to go further into the infinite intricacies of dynamical systems than would be possible using purely mathematical techniques. The chaotic scattering of particles in potential systems becomes something to be observed numerically (experimentally) and carefully unravelled. Just as in mathematical physics, the correspondence between the models and some (ideal?) reality is questionable, so, in this form of physical mathematics, the nature of the conclusions drawn is unclear. Even so, Ott has managed to capture the beauty of this subject in a way that should motivate and inform the next generation of students in applied dynamical systems.

Paul Glendinning is in the Department of Mathematics and Theoretical Physics, University of Cambridge, Silver Street, Cambridge CB3 9EW, UK. - much more important than the mathe-

\section{Genetic fusion}

\section{J. Delharty}

Chromosomes: A Synthesis. By Robert P. Wagner, Marjorie P. Maguire and Raymond L. Stallings. Wiley-Liss: 1993. Pp. 523. $£ 75.00, \$ 89.95$.

CHROMOSOMES are currently fashionable mainly because of the rapidly expanding field of molecular cytogenetics and its many applications in human, mammalian and evolutionary genetics. Attention has also focused on the chromosomal assignment of genes as a starting point for their isolation by the Human Gene Mapping Project. So it is undoubtedly a good time to bring out a book that attempts to cover this fusion of classical genetics and molecular biology. Chromosomes does this with considerable success.

In a sense, the title is misleading. From the central core of topics related to chromosomes, the book branches out to include almost all of modern genetics. For example, the chapter entitled "Basic chromosome structure" also covers topics such as reassociation kinetics, formation and cloning of DNA molecules, DNA sequencing methods and higher-order organization of chromatin. "Chromosomes and the cell cycle" includes a good mini-review of eukaryotic DNA repair and "Variations in chromatin organization and amount" has a section on transposable elements that includes retroviruses and their relation to human protooncogenes.

The book will be a good source of reference and up-to-date information for advanced students of genetics, giving a lead into a wide variety of aspects. In addition to some historical coverage there are many recent examples, principally from Drosophila, human and mammalian genetics, with relevant photographic illustrations, although with occasionally less than accurate captions. In general, the figures are clear and informative, but there are lapses into amateurism where the chromosomes appear as squiggles and the labels are microscopically small. More than 50 pages of references are usefully given as a chunk at the end of the book, but organized by chapter for ease of location. The price will be beyond a student budget but librarians and tutors would be well advised to keep copies: it is a volume that will be much sought after. $\square$

J. Delharty is in the Department of Genetics and Biometry, University College London, 4 Stephenson Way, London NW1 2HE, UK.

Also recently published is Sex Chromosomes and Sex Determination in Vertebrates by Alberto '. Solari (CRC Press, \$149.95). 